\title{
Role of 2d Ultrasound, 3d Ultrasound And Mri in The Diagnosis of Mullerian Duct Anomalies
}

\author{
Gaur Meenakshi ${ }^{1}$ • Gaur Smita $^{2}$ • Verma Vikas ${ }^{3} \cdot$ Khuteta R.P $^{4}$. \\ ${ }^{1}$ Senior Resident Obstetrics \& Gynaecology, Sms Medical College, Jaipur, Rajasthan, India \\ ${ }^{2}$ House Surgeon Obstetrics \& Gynaecology Jln Medical College, Ajmer. \\ ${ }^{3,4}$ Senior Resident Deptt Of Orthopedics, Sms Medical College, Jaipur, Rajasthan, India \\ Khuteta R.P, Professor Sms Medical College, Jaipur
}

\begin{abstract}
Objective : To evaluate and compare the diagnostic accuracies of 2D,3D Ultrasonography and Magnetic Resonance Imaging in the diagnosis of Mullerian Duct Anomalies.

Setting: Tertiary care centre

Design: analytical study

Method: 50 outpatient women presenting with the complaints of primary amenorrhea, primary infertility, pregnancy wastage and menstrual abnormalities \& suspicious of mullerian duct anomalies were enrolled in the study and subjected to clinical examination, $2 D \& 3 D$ Ultrasonography and Magnetic Resonance Imaging.

Results: MRI was considered as the gold standard and sensitivity and specificity of each diagnostic modality is calculated. 3D ultrasound diagnosed 11 true negative cases, 33 cases as true positive and 6 as false negative cases. MRI diagnosed 11 cases as true negative and 39 cases as true positive. Thus 3D ultrasound showed $85 \%$ sensitivity and 100\% specificity in diagnosing Mullerian Duct Anomalies; and MRI has 100\% sensitivity and specificity in diagnosing Mullerian Duct Anomalies.

Conclusion: the sensitivity and specificity of 3D ultrasonography in diagnosing Mullerian Duct Anomalies is better than2D Ultrasonography and comparable to that of MRI.Hence it is a better alternative, cost effective, acceptable and convenient to the patients.
\end{abstract}

Keywords: 2D, 3D, MRI, MDA

\section{Introduction}

Mullerian duct anomalies (MDA) results from non fusion and non development of Mullerian Duct. It occurs in 1 to $1.5 \%$ of the women Mullerian Duct anomalies occur due development defect in either vertical or lateral fusion, or resorption failure of the mullerian ducts ${ }^{1}$.

Women with MDA can present with serious complaints like:

- Primary amenorrhea,

- primary infertility,

- pregnancy wastage and

menstrual disturbances.

The prevalence of Mullerian Duct Anomalies is $0.4 \%$ of general population and in $4 \%$ of infertile women $^{1,2}$

Hence, accurate diagnosis of various subtypes of MDA as per American Fertility Society Classification is of great importance for better management.

Imaging is one of the most essential modality for diagnosis, management and reproductive counselling in patients with MDA's.

MRI is accepted as highly accurate tool for the evaluation of ,Mullerian Duct Anomalies and thus commonly used for clinical practice it gives detailed delineation of uterovaginal anatomy, and is non invasive with no danger of ionising radiation.

While MRI is useful option is the diagnosis of mullerian anomalies having proved its excellent efficacy, 3D ultrasonography represent a valid alternative $\mathrm{e}^{3,4,5,6}$. It yields picture very similar to MRI.

2D ultrasonography can be used as initial diagnostic tool but it is less sensitive than 3D USG and MRI in diagnosing and classifying Mullerian Duct Anomalies.

In clinical practice, the results of the MRI examination are used by the clinician in the context of a comprehensive clinical assessment scheme to reach the final clinical diagnosis. Information obtained from pelvic examination, laparoscopy, office hysteroscopy, or other imaging examinations such as sonography, sonohysterography, and hysterosalpingography differs from the type of information that complements the information that complements the information gained from MRI. 
The purpose of our study was to prove that 3D ultrasound is better alternative, cost effective and convenient diagnostic tool and comparable to MRI in diagnosing Mullerian Duct Anomalies.

\section{Method}

This was Hospital based analytical study conducted in the Department of Obstetrics and Gynaecology, Mahila Chikitsalaya, SMS Medical College, Jaipur from April 2012 till March 2013.

\section{Selection of cases.}

50 outpatient women patients presenting with the complaints of primary amenorrhea, primary infertility, recurrent pregnancy loss or any menstrual disturbances and having clinical suspicion of Mullerian Duct Anomalies were included in the study. These women were first subjected to clinical examination including per speculum and per vaginal examination (except unmarried women).

They further underwent 2D, 3D Ultrasonography and MRI in order to confirm our findings.

2D and 3D ultrasonography was performed using Real time Toshiba Nemio X series model SSA 380A ultrasonography machine equipped with convex transabdominal probe..

All underwent MRI after 3D \& 2D Ultrasonography and physical examination.MRI was performed using a Philips Healthcare 3 Tesla Ingenia MRI machine. All cases included coronal high-resolution T2weighted turbo spin echo imaging.

\section{Results}

There is wide variation in the presentation of mullerian duct anomalies demographically as most cases belongs to urban areas which may be due to easy accessibility to the health care facilities.

Table No.-1 Distribution of finding of uterus according to 2D, 3D USG and MRI

\begin{tabular}{|l|l|l|l|}
\hline \multirow{2}{*}{ Uterus } & \multicolumn{2}{l|}{ Evaluation Procedure } \\
\cline { 2 - 4 } & 2D- USG & 3D-USG & MRI \\
\hline Normal & 24 & 13 & 11 \\
& & & \\
\hline & 14 & 9 & 7 \\
Absent & $(28.00)$ & $(18.00)$ & $(14.00)$ \\
\hline & 7 & 12 & 15 \\
Hypoplastic & $(14.00)$ & $(24.00)$ & $(30.00)$ \\
\hline & 3 & 7 & 9 \\
Bicornuate & $(6.00)$ & $(14.00)$ & $(18.00)$ \\
\hline & 1 & 0 & 1 \\
Subseptate uterus & $(2.00)$ & $(0.00)$ & $(2.00)$ \\
\hline & 1 & 2 & 2 \\
Unicornuate uterus & $(2.00)$ & $(4.00)$ & $(4.00)$ \\
\hline & 0 & 3 & 2 \\
Septate & $(0.00)$ & $(6.00)$ & $(4.00)$ \\
\hline & 0 & 2 & 2 \\
Arcuate & $(0.00)$ & $(4.00)$ & $(4.00)$ \\
\hline & 0 & 1 & 1 \\
Didelphic & $(0.00)$ & $(2.00)$ & $(2.00)$ \\
\hline & 0 & 1 & 0 \\
Infantile uterus & $(0.00)$ & $(2.00)$ & $(0.00)$ \\
\hline
\end{tabular}

Table 2: comparison Between 2d Ultrasound And Mri Findings In Mullerian Duct Anomalies

\begin{tabular}{|c|c|c|c|c|c|c|c|c|c|}
\hline \multirow[t]{2}{*}{ 2d Uterus } & \multicolumn{9}{|c|}{ Mri Findings } \\
\hline & $\begin{array}{l}\text { Bicornuate } \\
\text { Uterus }\end{array}$ & $\begin{array}{l}\text { Didelphic } \\
\text { Uterus }\end{array}$ & $\begin{array}{l}\text { Septate/ } \\
\text { Uterus }\end{array}$ & $\begin{array}{l}\text { Unicornuate } \\
\text { Uterus }\end{array}$ & $\begin{array}{l}\text { Absent } \\
\text { Uterus }\end{array}$ & $\begin{array}{l}\text { Arcuate } \\
\text { Uterus }\end{array}$ & $\begin{array}{l}\text { Hypoplastic } \\
\text { Uterus }\end{array}$ & Normal & Total \\
\hline Absent & & & & & $7^{*}$ & & $7^{\#}$ & & 14 \\
\hline Bicornuate & $1^{*}$ & $1^{\#}$ & & & & $1^{\#}$ & & & 3 \\
\hline Hypoplastic & & & & & & & $7^{*}$ & & 7 \\
\hline Normal & $8^{\#}$ & & $2^{\#}$ & $1^{\#}$ & & $1^{\#}$ & $1^{\#}$ & $11^{*}$ & 24 \\
\hline $\begin{array}{l}\text { Subseptate } \\
\text { /Septate } \\
\text { Uterus }\end{array}$ & & & $1^{*}$ & & & & & & 1 \\
\hline $\begin{array}{l}\text { Unicornuate } \\
\text { Uterus }\end{array}$ & & & & $1^{*}$ & & & & & 1 \\
\hline Areunte & & & & & & & & & \\
\hline Grand Total & 9 & 1 & 3 & 2 & 7 & 2 & 15 & 11 & 50 \\
\hline
\end{tabular}


$X^{*}$ :-same findings of usg and mri in same patient

$X^{\#}$ :- different findings of usg and mri in same patient

Table 3: Comparison Between 3d Ultrasound And Mri In The Diagnosis Of Mullerian Duct

Anomalies

\begin{tabular}{|c|c|c|c|c|c|c|c|c|c|}
\hline \multirow{2}{*}{ 3d Uterus } & \multicolumn{9}{|c|}{ Mri Findings } \\
\hline & $\begin{array}{l}\text { Bicornuate } \\
\text { Uterus }\end{array}$ & $\begin{array}{l}\text { Didelphic } \\
\text { Uterus }\end{array}$ & $\begin{array}{l}\text { Septate } \\
\text { Uterus }\end{array}$ & $\begin{array}{l}\text { Unicornuate } \\
\text { Uterus }\end{array}$ & $\begin{array}{l}\text { Absent } \\
\text { Uterus }\end{array}$ & $\begin{array}{l}\text { Arcuate } \\
\text { Uterus }\end{array}$ & $\begin{array}{l}\text { Hypoplastic } \\
\text { Uterus }\end{array}$ & Normal & Total \\
\hline Absent & & & & & $7^{*}$ & & $2^{\#}$ & & 9 \\
\hline Arcuate & & & & & & $2^{*}$ & & & 2 \\
\hline Bicornuate & $7^{*}$ & & & & & & & & 7 \\
\hline Didelphic & & $1^{*}$ & & & & & & & 1 \\
\hline Hypoplastic & & & & & & & $12^{*}$ & & 12 \\
\hline Normal & $1^{\#}$ & & $1^{\#}$ & & & & $1^{\#}$ & $11^{*}$ & 14 \\
\hline Septate & $1^{\#}$ & & $2^{*}$ & & & & & & 3 \\
\hline $\begin{array}{l}\text { Unicornuate } \\
\text { Uterus }\end{array}$ & & & & $2^{*}$ & & & & & 2 \\
\hline Grand Total & 9 & 1 & 3 & 2 & 7 & 2 & 15 & 11 & 50 \\
\hline
\end{tabular}

Table 4 Sensitivity And Specificity Of 2d Ultrasound And Mri In Diagnosing Mullerian Duct Anomalies

\begin{tabular}{|l|l|l|l|}
\hline \multirow{2}{*}{$\begin{array}{l}2 \mathrm{D} \\
\text { findings }\end{array}$} & \multicolumn{2}{|l|}{ MRI Findings } & Total \\
\cline { 2 - 3 } & Positive & Negative & \\
\hline Positive & 15 & 1 & 16 \\
& $(30.00)$ & $(2.00)$ & $(32.00)$ \\
\hline Negative & 24 & 10 & 34 \\
& $(48.00)$ & $(20.00)$ & $(68.00)$ \\
\hline Total & 39 & 11 & 50 \\
& $(78.00)$ & $(22.00)$ & $(100.00)$ \\
\hline
\end{tabular}

True positive $(\mathrm{MRI})=39$

True Negative $(\mathrm{MRI})=11$

True Positive $=(2 \mathrm{D})=15$

False Positive $(2 \mathrm{D})=1$

True Negative $(2 \mathrm{D})=10$

False Negative $(2 \mathrm{D})=24$

Table 5: Sensitivity And Specificity Of 3d Ultrasound And Mri In Diagnosing Mullerian Duct Anomalies

\begin{tabular}{|l|l|l|l|}
\hline \multirow{2}{*}{$\begin{array}{l}\text { 3D } \\
\text { findin }\end{array}$} & \multicolumn{2}{|l|}{ MRI Findings } & $\begin{array}{l}\text { Tota } \\
1\end{array}$ \\
\cline { 2 - 4 } & Positive & Negative & \\
\hline Positive & 33 & 0 & 33 \\
& $(66.00)$ & $(0.00)$ & $(66$. \\
& & & $00)$ \\
\hline Negative & 6 & 11 & 17 \\
& $(12.00)$ & $(22.00)$ & $(34$. \\
& & 11 & $00)$ \\
\hline Total & 39 & $(22.00)$ & 50 \\
& $(78.00)$ & & $.00)$ \\
\hline
\end{tabular}

Sensitivity $=0.85=85 \%$

Specificity $=1=100 \%$

True positive $(\mathrm{MRI})=39$

True Negative $(\mathrm{MRI})=11$

True Positive $=(3 \mathrm{D})=33$

False Positive $(3 \mathrm{D})=0$

True Negative $(3 \mathrm{D})=11$

False Negative $(3 \mathrm{D})=6$

Sensitivity $=0.38=38 \%$

Specificity $=.91=91 \%$ 
Majority of the cases were diagnosed both by 3D USG and MRI.But 2D ultrasound was not able to diagnose and classify many of the Mullerian duct anomalies. The sensitivity and specificity of 2D ultrasound was less as compared to 3D ultrasonography and MRI in this study. But the concordance between 3D Ultrasound and MRI was very good.3D USG and MRI had comparable sensitivity and specificity (Table-1)

According to this study 2D USG is less sensitive in diagnosing mullerian duct anomalies but can be use as initial diagnostic tool in suspected cases of mullerian duct anomalies, but as the False negative rates are high with 2D ultrasound even if the findings are normal in 2D ultrasound further evaluation is needed.(Table2) 3D Ultrasound can accurately diagnose most of the cases of mullerian duct anomalies as MRI does. It can be as reliable as MRI in diagnosing Mullerian Duct Anomalies. Its specificity is comparable to MRI but it is less sensitive in diagnosing MDA's as compared to MRI.(Table-3)

MRI is 100\% sensitive and specific in diagnosing Mullerian Duct Anomalies whereas 2D Ultrasound has only 38\% sensitivity and 91\% specificity in diagnosing Mullerian Duct Anomalies. Thus it can be concluded from above discussion that 2D ultrasound is inadequate in diagnosing in Mullerian Anomalies and cannot be use as diagnostic modality for Mullerian Anomalies, but it can be use as initial screening tool.

(Table-4)

3D Ultrasound is as specific in diagnosing mullerian duct anomalies as MRI but it is less sensitive as compare to MRI,i.e.it is $100 \%$ specific in diagnosing mullerian duct anomalies but its sensitivity is $85 \%$ as compared to MRI which is $100 \%$ sensitive in diagnosing mullerian duct anomalies. 3D ultrasound can be use as a diagnostic tool in diagnosing MDA's in place of MRI which is less costlier and easy to perform and can give diagnosis comparable to MRI if 3D ultrasound is carried out in conjunction with complete gynecological examination then its accuracy is comparable to MRI in diagnosing and classifying Mullerian Duct anomalies.MRI should be preserved for doubtful and complex cases.(Table-5)

\section{Discussion}

There is wide variation in the presentation of mullerian duct anomalies demographically as most cases belongs to urban areas which may be due to easy accessibility to the health care facilities.

In the present study maximum no. of patients were presented with the complaints of primary amenorrhea followed by primary infertility and recurrent pregnancy loss. These patients were subjected to physical examination (per speculum and per vaginal examination except in unmarried female). On suspicion of mullerian anomalies on the basis of symptoms and physical examination were subjected to 2D ultrasonography, 3D ultrasonography and Magnetic Resonance Imaging.

Out of 50 patients, 3D Ultrasound diagnosed 11 cases as true negative as MRI does. In this study 39 cases had mullerian duct anomalies.MRI was able to diagnose all but 3D ultrasonography diagnosed 33 as true positive and 6 as false negative.

In contrast, Deutch TD conducted a study in 2008 in which he concluded that Magnetic Resonance Imaging is $100 \%$ to $28.6 \%$ sensitive and $100 \%$ to $66 \%$ specific in correctly categorising MDAs.3D Ultrasonography is $100 \%$ to $98 \%$ sensitive and $100 \%$ specific in correctly categorising MDAs

2D ultrasonography diagnosed 10 cases as true negative out of 11 but only 15 cases as true positive and 24 as false negative out of 39 true positive cases.

Saravelo ${ }^{7}$ Sh in June 2008 et al conducted a study in which he concluded that 2D Ultrasound is less accurate and thus are inadequate for diagnostic purposes in MDA's but can be use as initial screening tool.

2D ultrasonography is 38\% sensitive and 91\% sensitive and 3D ultrasonography is $85 \%$ sensitive and $100 \%$ specific in diagnosing mullerian duct anomalies as compared to MRI which is $100 \%$ sensitive and specific in diagnosing mullerian duct anomalies

In 1998 Huang Ke et al published an article in which he demonstrated that 3D ultrasonography is $100 \%$ sensitive and specific in diagnosing congenital uterine anomalies.

\section{Conclusion}

In the present study it was found that 2D ultrasonography is less accurate in diagnosing and classifying mullerian duct anomalies. It is not a reliable tool but can be use as initial screening method if there is suspicion of mullerian duct anomalies. On the other hand 3D Ultrasonography is comparable to MRI in diagnosing and classifying mullerian anomalies. Moreover it is cost effective and easily acceptable and convenient for the patient. Hence, 3D ultrasonography should be considered as first line investigation in women with MDA.

\section{References}

[1]. Byrne J, Nussbaum-Blask A, Taylor WS, Rubin A, Hill M, O’Donnell R, Shulman S. Prevalence of Mullerian duct anomalies detected at ultrasound. Am J Med Genet 2000; 94: 9-12.

[2]. Ashton D, Amin HK, Richart RM, Neuwirth RS. The incidence of asymptomatic uterine anomalies in women undergoing transcervical tubal sterilization. Obstet Gynecol 1988; 72: 28-30 
[3]. Carrington BM, Hricak H, Nuruddin RN, Secaf E, Laros RK Jr, Hill EC. Mullerian duct anomalies: MR imaging evaluation. Radiology 1990; 176: 715-720.

[4]. Pellerito JS, McCarthy SM, Doyle MB, Glickman MG, DeCherney AH. Diagnosis of uterine anomalies: relative accuracy of

[5]. MR imaging, endovaginal sonography and hysterosalpingography. Radiology 1992; 183: 795-800.

[6]. Fedele L, Dorta M, Brioschi D, Massari C, Candiani GB. "Magnetic resonance evaluation of double uteri." Obstet Gynecol

[7]. Fischetti SG, Politi G, Lomeo E, Garozzo G. Magnetic resonance in the evaluation of Mullerian duct anomalies. Radiol Med 1995; 89: 105-111

[8]. Saravelo SH "Prevalence and diagnosis of congenital uterine anomalies in women with reproductive failure: a critical appraisal 0.1093/humupd/dm018 Epub 2008 June 6. 